Portland State University

PDXScholar

$8-1-2020$

\title{
The Effects of Variations in Confession Evidence and Need for Cognition on Jurors' Decisions
}

\author{
Kelsey S. Henderson \\ Portland State University, kelsey.henderson@pdx.edu \\ Lora M. Levett \\ University of Florida
}

Follow this and additional works at: https://pdxscholar.library.pdx.edu/ccj_fac

Part of the Criminology and Criminal Justice Commons

Let us know how access to this document benefits you.

\section{Citation Details}

Henderson, K. S., \& Levett, L. M. (2020). The effects of variations in confession evidence and need for cognition on jurors' decisions. Psychology, Public Policy, and Law, 26 (3), 245-260. https://doi.org/ 10.1037/LAW0000233

This Pre-Print is brought to you for free and open access. It has been accepted for inclusion in Criminology and Criminal Justice Faculty Publications and Presentations by an authorized administrator of PDXScholar. Please contact us if we can make this document more accessible: pdxscholar@pdx.edu. 
(C)American Psychological Association, 2020. This paper is not the copy of record and may not exactly replicate the authoritative document published in the APA journal. Please do not copy or cite without author's permission. The final article is available, upon publication, at: http://dx.doi.org.proxy.lib.pdx.edu/10.1037/law0000233

Henderson, K. S. \& Levett, L. M. (2020). The Effects of Variations in Confession Evidence and Need for Cognition on Jurors' Decisions. Psychology, Public Policy, and Law, 26(3), 245-260. http://dx.doi.org.proxy.lib.pdx.edu/10.1037/law0000233

\begin{abstract}
The reliability of a confession partially depends on the interrogation methods used and the confession's content. Confronting suspects with evidence gives a suspect knowledge of nonpublic details, increasing the likelihood of a false confession (Gudjonsson \& Pearse, 2011; Leo, 2009), and makes the confession harder to judge as more or less reliable. That is, if a confession is consistent with case facts but details of the crime were communicated to the suspect during interrogation, it is difficult to judge whether the confession is a product of the suspect's knowledge of the crime or the details that were communicated during the interrogation. The objective of this manuscript was to examine whether jurors consider the interrogation technique and source of consistent knowledge in judging the reliability of confession evidence. In two studies, participants read a trial summary in which the defendant's confession was consistent $\mathrm{v}$. inconsistent with case facts and evidence was withheld v. disclosed during the interrogation. In study two, we also examined for moderating effects of need for cognition (NC). Overall, participants were attuned to confession-case facts consistency in making decisions; furthermore, in study two, this effect interacted with evidence disclosure on a number of measures. If the confession was consistent, participants rated the strength of evidence and reliability of the confession higher, and impression of the interrogation more positively, when evidence was withheld during the interrogation rather than disclosed. NC did not moderate these effects. Overall, findings suggest participants are somewhat sensitive to variations in confession evidence.
\end{abstract}

Keywords: confessions, jury decision-making, interrogations, strategic use of evidence, need for cognition 
The Effects of Variations in Confession Evidence and Need for Cognition on Jurors' Decisions

Confessions, repeated denials, assertions of innocence, and exculpatory and inculpatory statements are all products of an interrogation. If a suspect has waived their Miranda rights (Miranda v. Arizona, 1966), these statements can be used at trial. One concern is if information in a confession did not originate with the suspect, but was disclosed during the interrogation. Sharing evidence in an interrogation could give an innocent suspect knowledge of non-public details of the crime, increasing the likelihood that should the suspect confess, he or she will incorporate those details in the false confession (Leo, 2009). 1 out of 4 individuals exonerated through exculpatory DNA evidence falsely confessed (DNA Exonerations in the United States, n.d.). False confessions can be full of inaccurate details and inconsistencies (Garrett, 2010), which theoretically could help fact finders spot a false confession (Henderson \& Levett, 2016). However, many false confessions contain accurate, non-public details known only to the perpetrator. These details are likely learned through the interrogation and incorporated into the false confession.

Confronting suspects with evidence at the beginning of an interrogation is a commonplace occurrence (Kassin, 2005). For example, in recalling his own false confession, John Kogut stated "Nothing was asked of me. Everything was told to me" (as cited in Garrett, 2010, pg. 1091). The inclusion of such detail increases the likelihood that jurors will view the confession as reliable (Appleby, Hasel, \& Kassin, 2013). Further, if the information included in a confession is consistent with crime facts, jurors are more likely to judge the confession as credible compared to if the confession is inconsistent with crime facts (Henderson \& Levett, 2016). However, a confession that is consistent with crime facts is not necessarily a reliable indicator of accuracy given that providing details during the interrogation can artificially inflate 
the consistency of a suspect's confession (Garrett, 2010). In the words of former St. Paul Police Chief upon realizing a false confession was given in his precinct, "You realize maybe you gave too much detail as you tried to encourage him, and he just regurgitated it back" (Drizin, Nirider, Nawoichyk, \& Tepfer, 2012, pg. 12).

Therefore, the reliability of a confession should be at least partially judged by the content of the confession (i.e., the consistency of the confession with the facts of the case) combined with the techniques used during the interrogation. In these studies, we examined if participants are sensitive to variations in the quality of confession evidence, defined by the consistency of the confession information with the details of the crime and the evidence disclosure strategy used in interrogation. In study one, we examined participants' abilities to examine the content of a confession (consistent $\mathrm{v}$. inconsistent with case facts) and the evidence disclosure technique used during the interrogation (evidence disclosed v. evidence withheld). In study two, we examined if need for cognition moderated participants' sensitivity to these variations.

\section{Interrogations and Confessions}

Research has demonstrated that jurors weigh confession evidence heavily (Kassin \& Neumann, 1997). Confession evidence affects verdict decisions even if that confession is stricken from the record, and regardless of the coerciveness of the interrogation (Kassin \& Sukel, 1997). Research examining jurors' sensitivity to variations in interrogation and confession evidence is mixed. For example, in one study, the number and type of tactics used in an interrogation did not influence juror verdicts (i.e., jurors were not sensitive to variations; Jones \& Penrod, 2016). Instead, jurors were influenced by the presence of a confession alone in their verdict decisions, and not the types of tactics used to elicit that confession. Similarly, confessions elicited under high-pressure interrogation techniques were perceived as less coercive if the 
confession led to the discovery of corroborating evidence than if it did not (Shaked-Schroer, Costanzo, \& Berger, 2015). This suggests that if a defendant confesses, jurors may discount the effects of coercive interrogation techniques (Shaked-Schroer et al., 2015). Other research suggests jurors may be sensitive to variations in confession evidence and interrogation techniques (Woestehoff \& Meissner, 2016). For example, in one study, jurors were more willing to convict in low-pressure interrogation conditions compared to medium- and high-pressure interrogation conditions (study one; Woestehoff \& Meissner, 2016). Furthermore, path analyses demonstrated that medium- and high-pressure interrogations led to more negative perceptions of the interrogation, which resulted in lower conviction rates (studies one and two). Another factor jurors should be attuned to in their evaluation of confession evidence is the content of the confession itself. That is, jurors should attend to whether the confession details are consistent with other evidence and case facts.

The consistency between content in a confession and crime facts can help indicate whether the confession is reliable or unreliable evidence (Leo \& Ofshe, 1998). There is some evidence to suggest that jurors are sensitive to variations based on consistency (Alceste, Crozier, \& Strange, 2019; Henderson \& Levett, 2016; Palmer, Button, Barnett, \& Brewer, 2016). For example, in one study, jurors rated the defendant's probability of guilt, strength of the evidence in the case, and reliability of the confession evidence higher and the defendant's character more negatively if the confession details were consistent with case facts versus if they were inconsistent (Henderson \& Levett, 2016). Similar findings have been reported in other research, showing that jurors were less likely to convict when they heard a confession inconsistent with verifiable facts compared to a consistent confession (Palmer et al., 2016). And, that at least in some instances, jurors accounted for whether consistent information in a confession came from a 
suspect or a police officer, although this effect was inconsistent across the two studies (Alceste et al., 2019). However, in examining cases of known false confessions, $74 \%$ contained discrepancies between the confession and case facts and the vast majority of those defendants were convicted by a jury trial (Garrett, 2010), indicating jurors are not always sensitive to the content of the confession in their verdict decisions.

An inconsistent confession should therefore be considered unreliable and possibly an indicator of innocence (Leo \& Ofshe, 1998). Other indicators of the reliability of the confession are that the confession includes non-public information and a level of accurate detail that cannot have been simply guessed (Leo \& Ofshe, 1998). However, research examining a subsample of proven false confessions found that $71 \%$ contained non-public details and $26 \%$ contained consistent information (Garrett, 2010). Therefore, a consistent confession is not necessarily an indicator of accuracy. Instead, it is an indicator that one should assess whether evidentiary information was shared with the suspect during the interrogation prior to the suspect's confession (Garrett, 2010). In examining the reliability of the confession, one must consider both the content of the confession and the techniques used during the interrogation and whether they could have contaminated the confession evidence.

\section{Approaches to the Interrogation}

Our research explores one key distinction between accusatorial and information gathering interrogation models- the presentation of evidence (for a greater discussion on different interrogation models and techniques see Kelly, Miller, Redlich, Kleinman, 2013). Accusatorial interrogations are common in the United States; for example, the Reid interrogation is a ninestep interrogation involving a number of different techniques (see Inbau, Reid, \& Buckley, 1986). The accusatorial model involves two phases: the interview (to determine if the individual 
is a suspect to be formally interrogated) and the formal interrogation (Meissner, Redlich,

Michael, Evans, Camilletti, Bhatt, Brandon, 2014). During the confrontation stage of the formal interrogation (for more see Kassin \& Gudjonnson, 2004), the officer confronts the suspect with real or falsified evidence of their guilt. Central to the research question of this manuscript, this confrontation can result in relaying information about the crime to the suspect. Importantly, disclosing of evidentiary information can be either intentional or by accident, but research suggests it is a frequent occurrence (more below; Leo, 1996).

Information gathering interviews are more common outside of the United States; for example, the PEACE model in United Kingdom, New Zealand, and Norway (Gudjonsson \& Pearse, 2011). Information gathering interviews are often thought of as "fact-finding" missions and emphasize the importance of truth gathering (Meissner et al., 2014). This model focuses on building rapport and stresses the importance of honesty, explaining the offense, and asking the suspect to give their version of events (Gudjonsson \& Pearse, 2011; Kassin, Drizin, Grisso, Gudjonsson, Leo, \& Redlich, 2010; Meissner et al., 2014).

Examining common strategies of accusatorial interrogations demonstrates that the actions of interrogators can lead to evidence contamination or sharing evidence of the crime with the suspect. Observations of 182 U.S. interrogations illustrated the frequency with which police officers disclose evidence during interrogations; in $85 \%$ of cases, officers confronted the suspect with evidence of guilt and in 30\%, confronted with false evidence of guilt (Leo, 1996). Investigators in the U.S. report using these techniques frequently; on a scale ranging from 1never to 5-always, the mean value for "confronting suspect with evidence of his guilt" was 3.90 and "implying or pretending to have independent evidence of guilt" was 3.11 (Kassin, Leo, Meissner, Richman, Colwell, Leach, \& La Fon, 2007). Similarly, in a sample of Canadian 
interrogations, $82 \%$ of interrogations involved confronting the suspect with existing evidence of guilt; this was the most common technique identified (King \& Snook, 2009). If evidence is disclosed early, suspects may say little to contradict the information given and may re-work their story to the police, who then can rely only on non-verbal cues to detect deception, rather than the information relayed by the suspect (Hartwig, Granhag, Stromwall, \& Kronkvist, 2006).

One clear difference between the accusatorial model and the information gathering model is the method in which information (i.e., evidence) is preserved, shared, and utilized during the interrogation. Accusatorial interrogations are more likely to involve disclosing evidence at the beginning of an interrogation, making the suspect aware of the incriminating evidence against them (Leo, 1996). In contrast, in information gathering interviews and in techniques for lie detection like the Strategic Use of Evidence technique, information is withheld until after suspects have given their version of events, and may not be disclosed at all (Hartwig et al., 2006; Hartwig Granhag, Stromwall, \& Vrij, 2005, Meissner et al., 2014).

By withholding evidence, the interrogator should be able to use the consistency or inconsistency between individuals' statements and case facts to separate liars from truth-tellers (Hartwig et al., 2006), thereby lowering the risk of a false confession. Withholding evidence during an interrogation also decreases the likelihood that an innocent individual will be made privy to non-public details (and consistent crime details) they might parrot back to the investigator in a false confession. The goal of withholding evidence is to increase deception detection in the interrogation room while simultaneously decreasing the likelihood of evidence contamination. In other words, this technique increases the chances that statements provided by the suspect are untainted by information shared, known only to the police (and perpetrator). 
Withholding information in the interrogation room should also increase the likelihood independent fact finders could use the characteristics of the confession to weigh the confession appropriately. A confession that is inconsistent with case facts should be weighed less heavily regardless of evidence disclosure; however, how a consistent confession should be weighed depends on whether evidence was disclosed during the interrogation. Theoretically, if a confession is consistent with case facts and interrogators withheld evidence, one can be more certain the confession was a product of the confessor's own knowledge and not information that was communicated by an interrogator compared to a consistent confession if evidence was disclosed early in the interrogation. In these studies, we examined jurors' sensitivity to variations in confession evidence by focusing on these aspects of confession-case facts consistency and evidence disclosure technique.

\section{Study One}

In this study, we examined participants' sensitivity to the consistency of a confession with case facts and whether evidence was disclosed or withheld during the interrogation as indicators of a more or less reliable confession. Based on past research (Henderson \& Levett, 2016), we first hypothesized a main effect of consistency on jurors' decisions. Specifically, we expected participants would be more likely to convict, rate the defendant's probability of guilt, strength of evidence, and reliability of the confession higher and rate the defendant more negatively in conditions in which the confession was consistent with the facts of the case compared to conditions in which the confession was inconsistent with the facts of the case.

Second, we expected this main effect to be qualified by a significant interaction between confession-case facts consistency and evidence disclosure on our dependent variables. That is, if participants properly considered the origin of the confession details, participants in conditions in 
which the confession was consistent with case facts should be more likely to convict, rate the defendant's probability of guilt, strength of evidence, and reliability of the confession higher, impression of the interrogation more positively, and the defendant more negatively if interrogators withheld evidence compared to conditions in which they disclosed evidence.

\section{Study One Method}

Design. To manipulate the consistency of the confession with the case facts, we manipulated the content of the case facts and the confession. In half of the conditions, participants read a case in which the victim was stabbed 1-2 times and was incredibly short (lower severity); in the other half participants read a case in which the victim was stabbed 38 times and was incredibly tall (higher severity). Similarly, in half of the conditions, the evidence included a confession in which the defendant confessed to stabbing the victim 1-2 times and that she was incredibly short (lower severity); in the other half the evidence included a confession in which the defendant confessed to stabbing the victim 38 times and that she was incredibly tall (higher severity). By crossing the case facts and confession content, we created inconsistent and consistent conditions, counterbalancing for low or high crime severity.

The study used a 2 (case facts: low vs. high severity) X 2 (confession: low vs. high severity) X 2 (evidence disclosure: disclosed v. withheld) between subjects factorial design. Participants were randomly assigned to one of the eight conditions. For ease of interpretation, we report results from a simplified design that collapsed across consistent and inconsistent conditions: 2 (confession/case facts: consistent v. inconsistent) X 2 (evidence disclosure: disclosed v. withheld). Results from the simplified and full design were the same.

Participants and Power. Sample size was estimated in a power analysis using G*Power 3.1 (Faul, Erdfelder, Buchner, \& Land, 2007). We used a small effect size for ANOVA analyses 
$(f=.20)$, with $\alpha=.05$ and power $=.90$ (recommended by Cohen, 1988). Using these criteria, we needed to collect at least 265 participants (roughly 33 per cell).

Participants were 356 jury-eligible U.S. citizens drawn from Amazon’s Mechanical Turk (MTurk) worker pool. All participants were over the age of 18 and a U.S. citizen (statutory requirements for jury service). MTurk is a crowd-sourcing tool that allows workers to complete tasks online for compensation; we paid participants $\$ 3.00$. Three attention check questions were included to ensure participants were paying attention to the questionnaire. These questions asked participants to indicate a particular response option as a method of assessing their participation (e.g., "This question is to check your attention. Select 'somewhat agree'."), and were imbedded throughout the survey. Participants who incorrectly answered these questions were excluded $(N$ =4). We also asked participants manipulation check questions to ensure they paid attention to our stimulus, remembered details correctly, and noticed the differences between the conditions (see questions below). Participants who failed manipulation checks were excluded $(N=65)$. Thus, the final sample included 287 participants, with cell sizes in the simplified design ranging from $N=63-80$. Analyses were conducted with the full sample and the general pattern of results stayed the same; full sample analyses are reported in supplemental materials.

The average age for the sample was 37 years old (range $20-69$ years old). The sample was $57.5 \%$ male, $42.2 \%$ female, and $0.3 \%$ transgender. $54.4 \%$ of participants had been called for jury duty, and $12.2 \%$ had served in the past. Participants were White $(79.1 \%)$, Black, nonHispanic (6.6\%), Asian (5.9\%), Hispanic (5.2\%) and other races/ethnicities (2.4\%). 2 participants $(0.7 \%)$ did not report race. Highest obtained education level varied across participants; $0.3 \%$ reported less than a high school degree, $13.9 \%$ a high school degree, $19.5 \%$ 
attended some college, $13.6 \%$ earned an associate's degree or technical degree, $43.2 \%$ earned a bachelor's degree, $2.1 \%$ attended some graduate school, and $7.3 \%$ earned a graduate degree.

Materials. The written trial stimulus used in this study was a murder trial modified from the wrongful conviction case of Earl Washington, Jr. (Washington v. Commonwealth, 1984). In the Washington case, there were many inconsistencies between the confession and the crime details. The trial began with judicial instructions and opening statements from the prosecution and defense attorney. The prosecutor presented officers' testimonies regarding the evidence, facts of the case, and confession. The case facts and confession details differed depending on condition. That is, the officers testified that the victim was stabbed 1-2 times and was incredibly short or was stabbed 38 times and incredibly tall. Similarly, the details of the confession were that the defendant admitted to stabbing the victim 1-2 times and that she was incredibly short or that he admitted to stabbing the victim 38 times and she was incredibly tall.

In evidence disclosed conditions, the officer testified that they followed the Reid model and that one common technique in this model involved confronting the suspect with evidence and case information at the beginning of the interrogation. He explained that the motivation behind doing this is to confront the suspect with the evidence in hopes that the suspect will feel pressured to confess. When asked what evidence he confronted the defendant with, the officer testified that he shared "some details" related to the victim and the murder.

In evidence withheld conditions, the officer testified that they used the Strategic Use of Evidence technique and that this involves withholding evidence from the suspect and using it later if necessary. He testified that they did not disclose evidence or information with the defendant and rather let the defendant talk and give his account. He explained that doing this helps officers decipher between truth-tellers and liars based on the consistency of the defendant's 
account and prevent individuals from gaining access to non-public information.

The defense presented witnesses, including the defendant who testified that the details in the confession were false and that he recanted his confession after signing the written document. The defendant's sister also testified that she did not believe her brother owned a piece of clothing that matched one found at the crime scene, but it was possible that he did. Finally, both the defense and prosecution gave their closing statements and the judge issued pattern jury instructions based on US Courts (Sixth Circuit Committee, 2019). Confession-case facts [in]consistency was reinforced throughout the trial stimulus. That is, if the confession and case facts were consistent, this was highlighted and emphasized by the prosecution in opening and closing statements, and during testimony. Similarly, when the confession and case facts were inconsistent, this was highlighted and emphasized by the defense attorney in opening and closing statements, and during testimony.

\section{Dependent Variables.}

Guilt ratings. Participants rendered a verdict (guilty or not guilty of murder) and rated the probability that the defendant committed the crime on a scale from $0 \%-100 \%$.

\section{Strength of evidence, reliability of the confession and impression of the interrogation.}

For these items, participants indicated agreement with a series of statements on 6-point Likerttype scales with 1 indicating strongly disagree and 6 indicating strongly agree. Items were analyzed in an exploratory factor analysis using maximum likelihood extraction and varimax rotation before combining into scales. The following scales were created: strength of evidence, reliability of the confession, and overall impression of the interrogation. See Table 1 for scale items and alpha reliability scores. 
Ratings of the defendant's character. Participants rated the defendant on a series of bipolar adjective pairs (Levett \& Kovera, 2008). All items were on a 7-point scale, with higher levels indicating a more positive rating (reverse-coded items indicated by $(\mathrm{R})$ ). Responses to the following items were averaged to create an overall impression of the defendant scale $(\alpha=.97)$ : trustworthy-untrustworthy (R), good-not good (R), honest-dishonest (R), respectable-not respectable $(\mathrm{R})$, accurate-inaccurate $(\mathrm{R})$, immoral-moral, unlikable-likable, not believablebelievable, not credible-credible, convincing-unconvincing (R), sincere-insincere (R), certainuncertain (R), intelligent-unintelligent (R), and competent-incompetent (R).

Manipulation checks. As stated above, we excluded participants who failed manipulation check questions assessing the presence of confession evidence, consistency between the confession and case facts, and type of interrogation technique used $(N=65)$. The following questions were used: (a) Did Fred Patrick confess to murdering Tiffany Albert? (yes or no) (confession manipulation check); (b) Was Fred Patrick's confession consistent with the other evidence? (yes or no) (consistency/inconsistency of the confession and case facts); and (c) The officer said which interrogation technique was used? (Reid technique, early evidence disclosure or Strategic Use of Evidence, withholding evidence until later) (type of interrogation technique). We also collected data on participants' ratings of the evidence disclosure of the interrogation, but given it was redundant with our manipulation checks we did not include it in the paper; it is available in supplemental materials.

Procedure. The Portland State University Institutional Review Board approved all materials and procedures prior to the collection of these data. Participants signed up for the study online through Amazon's Mechanical Turk (MTurk) and were directed to Qualtrics to complete the study. MTurk is a crowd-sourcing data collection tool that offers a more diverse sample than 
traditional student samples (Sheehan, 2018). In addition, data collected through MTurk can be as valid as other data collection tools, particularly when safeguards such as manipulation and attention checks are utilized (Sheehan, 2018). After indicating consent, participants completed a voir dire questionnaire, read a trial stimulus (randomly assigned to condition), and answered the trial questionnaire. Participants took on average 18 minutes to complete the study. See the supplemental materials for the trial stimulus, voir dire questionnaire, and study questionnaire.

\section{Study One Results}

To test our hypotheses, we ran a series of regression analyses to assess the effects of the main effects and interactions on our dependent measures. Recall that we expected a main effect of confession-case facts consistency on jurors' decisions. However, we expected this main effect would be qualified by an effect of the interaction (confession-case facts consistency X evidence disclosure) on our dependent measures in that participants who heard a consistent confession would differentiate between confessions obtained in interrogations in which evidence was disclosed versus withheld. We organized the results by dependent measure given that all analyses were testing the same two hypotheses for the various measures.

Effects of case-facts consistency and evidence disclosure on verdict. We ran a logistic regression to test the effect of confession-case facts consistency, evidence disclosure, and their interaction on verdict. The overall model was significant, $\chi^{2}(3)=17.08, p=.001$. However, there were no significant main or interaction effects; confession-case facts consistency, $B=0.65$, $S . E=0.46$, Wald's $\chi^{2}(1)=2.04, p=.153, \exp (B)=1.91,95 \% C I[0.79,4.67]$, evidence disclosure, $B=-0.04$, S.E $=0.48$, Wald's $\chi^{2}(1)=0.01, p=.927, \exp (B)=0.96,95 \% C I[0.38$, 2.45], and the interaction, $B=0.80, S . E=0.62$, Wald's $\chi^{2}(1)=1.67, p=.196, \exp (B)=2.23$, $95 \%$ CI $[0.66,7.53]$ 


\section{Effects of case-facts consistency and evidence disclosure on probability of guilt and}

strength of evidence ratings. We ran a MANOVA to test the effect of the independent variables and their interaction on participants' probability of guilt measure and perceptions of the strength of evidence scale. There was a main effect of confession-case facts consistency on the DVs, $\lambda=$ $.90, F(2,279)=16.24, p<.001, \eta^{2}=.10$. We found a main effect of confession-case facts consistency on participants' probability of guilt and strength of evidence ratings with trends in the hypothesized direction (see Table 2). All other effects were not significant; the effect of evidence disclosure, $\lambda=.98, F(2,279)=2.95, p=.054, \eta^{2}=.02$, and the interaction, $\lambda=.99, F$ $(2,279)=1.57, p=.210, \eta^{2}=.01$.

\section{Effects of case-facts consistency and evidence disclosure on participants' ratings of} the confession, interrogation, and defendant. To test whether participants in consistent confession-case facts conditions were sensitive to the possible origin of the confession evidence, we then ran an ANOVA with confession-case facts consistency, evidence disclosure, and the interaction between these variables as the IVs and participants' ratings of the confession as the DV. There was a significant main effect of consistency with trends in the hypothesized direction (see Table 2). All other effects were not significant; evidence disclosure, $F(1,280)=2.14, p=$ $.144, \eta^{2}<.01$, and the interaction, $F(1,280)=3.79, p=.053, \eta^{2}=.01$.

To test the effect of confession-case facts consistency and evidence disclosure on jurors' ratings of the interrogation, we ran an ANOVA with confession-case facts consistency, evidence disclosure, and the interaction between these two variables as the IVs. The main effects of confession-case facts consistency and evidence disclosure were significant, $F(1,282)=18.00, p$ $<.001, \eta^{2}=.06$ and $F(1,282)=14.34, p<.001, \eta^{2}=.05$, respectively. Participants rated their impression of the interrogation more positively in conditions in which the confession and case 
facts were consistent versus inconsistent (see Table 2). Additionally, participants rated their impression of the interrogation more positively in evidence withheld conditions than evidence disclosed conditions (see Table 3 ). The effect of the interaction was not significant, $F(1,282)=$ $1.56, p=.213, \eta^{2}=.01$

Last, we ran an ANOVA with confession-case facts consistency, evidence disclosure, and the interaction between these two variables as the IVs and the scale representing participants' perceptions of the defendant as DV. The main effects of confession-case facts consistency and evidence disclosure were significant, $F(1,280)=4.28, p=.040, \eta^{2}=.02$ and $F(1,280)=7.50$, $p=.007, \eta^{2}=.03$, respectively. These main effects were qualified by a significant interaction, $F$ $(1,280)=4.16, p=.042, \eta^{2}=.02$. Within evidence withheld conditions, there was a simple main effect of confession-case facts consistency, $p=0.003$. Participants in evidence withheld conditions who heard an inconsistent confession rated the defendant more positively $(M=3.88)$ than those in consistent conditions $(M=3.31), d=0.51,95 \% C I[0.18,0.84]$. The effect of confession-case facts consistency within evidence disclosed conditions was not significant, $p=$ $.984, d=0.00,95 \% C I[-0.34,0.34]$. See Tables $2-3$ for means for main effects. Full results for the interaction effects are reported in supplemental materials, Table 4.

\section{Study One Discussion}

Overall, in this study, participants were sensitive to consistency between the confession and case facts. Participants rated the defendant's probability of guilt, strength of evidence, and reliability of the confession higher, and their impression of the interrogation more positively, in consistent conditions compared to inconsistent. We also found that whether evidence was withheld or disclosed affected impressions of the interrogation. Participants in evidence withheld conditions had more positive impressions of the interrogation than those in evidence disclosed 
conditions. Importantly, the interaction between confession-case facts consistency and evidence disclosure was not significant on most dependent measures; this would have indicated that participants were sensitive to where confession details could have originated.

We did see the expected interaction between confession-case facts consistency and evidence disclosure on one measure: participants' evaluations of the defendant. Participants in evidence withheld conditions who heard an inconsistent confession rated the defendant more positively than those who heard a consistent confession, suggesting that participants perceived the defendant who was not made privy to case details during the interrogation and provided inconsistent information in his confession more positively than a defendant who was not given case details and provided consistent information.

In this study, participants did not largely consider the potential source of information in evaluating the consistency of the confession. Instead, we found that participants considered consistency in their evaluations of evidence, and some support for the notion that participants consider evidence disclosure techniques in their decision making. However, we did not see effects of our independent variables on verdict, indicating that participants' evaluations of evidence did not ultimately carry over to the dichotomous verdict decision.

In considering confession evidence, theoretically participants should evaluate the totality of the confession evidence, considering both the content of the confession and how that information was attained (either through personal knowledge of the crime or possibly through the interrogation). However, we did not see a great deal of support for our hypothesis that participants would process evidence in this way. One possibility is that participants may differ in their motivation and/or ability to process the information and evaluate its content. That is, it is possible that some individuals are more motivated than others to process the complex 
information in the confession evidence. Furthermore, some individuals may be more likely than others to have the ability to process the confession evidence, correctly determining that evidence gained through the interrogation itself may be unreliable. In study two, we explored individual differences in whether some participants may be more able than others to consider the nuances of the confession evidence.

Need for cognition. Social psychological literature suggests that jurors who are differentially motivated or who have different abilities may process trial information differently (Bornstein, 2004; McAuliff \& Kovera, 2008; Sommers \& Kassin, 2001). In examining juror decisions, the Elaboration Likelihood and Heuristic Systematic Models of persuasion (Petty \& Wegener, 1998) provide a theoretical framework for understanding how jurors consider and make decisions about evidence (Petty \& Cacioppo, 1986; Chaiken, Liberman, \& Eagly, 1989). Applied to juror decision making, these models help explain how jurors are persuaded to particular decisions at trial.

Individuals using the heuristic or peripheral route to process information are influenced more by heuristics (e.g., attorney attractiveness, number of experts per side) than the information's quality (Petty \& Wegener, 1998). Heuristic processing is more accessible and people engage in heuristic processing when they are unmotivated or unable to use systematic processing (Chaiken, et al., 1989). Individuals using the systematic or central route possess the motivation and ability to carefully scrutinize information and base their decisions on the information's merit and quality (Petty \& Wegener, 1998). Individuals engaging in systematic processing use a comprehensive orientation to assess and scrutinize information for relevance and importance before forming a judgment.

In our initial study, a person processing systematically would theoretically notice the 
consistency of the confession evidence with the case facts and the origin of that information. However, if a person's motivation or ability to process information is lacking, he or she may rely on heuristics or other cues that substitute for accuracy (in this case, perhaps the consistency of the confession information without considering where the information originated).

One individual factor that might influence jurors' motivation to process information systematically is need for cognition. Need for cognition (NC) is defined as individual differences in one's tendency to engage in and enjoy thinking (Cacioppo \& Petty, 1982). It can be examined as a moderating variable to help determine which route to persuasion individuals use (Cacioppo \& Petty, 1982). High-NC individuals tend to employ more cognitive thought and evaluate the merits of information systematically more than low-NC individuals (Cacioppo, Petty, Kao, \& Rodriguez, 1986), whereas, low-NC individuals tend to be more influenced by superfluous cues like heuristics that are not necessarily relevant to the message than high-NC individuals (e.g., attractiveness of an endorser; Haugtvedt, Petty, \& Cacioppo, 1992).

Past research suggests that NC can affect jurors' decisions about trial evidence (Bornstein, 2004; McAuliff, \& Kovera, 2008; Sommers \& Kassin, 2001). In one study, low-NC jurors who heard a defense expert present anecdotal evidence judged the defendant as less likely to have caused the plaintiff's injuries than jurors who did not hear anecdotal evidence, whereas high-NC jurors were not affected by the presence or absence of anecdotal evidence (Bornstein, 2004). In another study, high-NC jurors were more attuned to variations in the internal validity of expert testimony evidence than low-NC jurors (McAuliff \& Kovera, 2008). Furthermore, NC has been shown to affect jurors' ability to disregard inadmissible evidence; high-NC jurors were more motivated to reach a just verdict and more sensitive to variations in inadmissible evidence compared to low-NC jurors (Sommers \& Kassin, 2001). 
These studies suggest NC is an important individual difference contributing to jurors' abilities to critically evaluate evidence. Thus, exploring NC related to jurors' evidence processing may give important clues about how to present evidence in a way to help jurors better process evidence or may be a first step in exploring the effectiveness of legal safeguards to help lower NC jurors better evaluate evidence (e.g., judicial instructions, expert testimony; as suggested in McAuliff \& Kovera, 2008). In this study, it is possible that NC may predict motivation to understand possible consequences of evidence contamination (i.e., confession consistency as a product of evidence disclosure during the interrogation), similar to how it has been shown to affect jurors' ability to evaluate expert and inadmissible evidence generally.

Importantly, jurors in our first study were randomly assigned to condition. That is, each condition likely contained both higher and lower NC jurors. If high-NC jurors noticed the origin of consistent confession information in evaluating the confession evidence and low-NC jurors did not, any effects may have been attenuated due to the differences in processing in these two groups. Thus, in study two we measured NC to explore whether NC moderated whether jurors processed confession evidence considering both the consistency of the confession evidence with the case facts and whether evidence was disclosed to the suspect during interrogation.

\section{Study Two}

Recall that in study one, participants were sensitive to variations in confession-case facts consistency, but largely did not perceive the consistency between confession evidence and case facts differently based on whether evidence was disclosed or withheld during the interrogation. It is possible that participants higher in NC (versus low) would make the connection between evidence disclosure and variations in confession evidence (i.e., NC may moderate participants' sensitivities to variations in confession evidence). 
Similar to study one, we first hypothesized a main effect of confession-case facts consistency on our dependent variables. Second, we predicted that this main effect would be qualified by a three-way interaction between $\mathrm{NC}$, evidence disclosure, and confession-case facts consistency. That is, we hypothesized that NC would moderate participants' sensitivities to variations in evidence disclosure and confession factors. Specifically, we expected that for highNC individuals, the effect of the interaction between consistency of the confession with case facts and evidence disclosure would be significant in that participants with high-NC in confession-case facts consistent conditions would be more likely to convict and rate the defendant's probability of conviction, strength of evidence, and reliability of the confession higher, impression of the interrogation more positively, and defendant more negatively if the interrogator withheld evidence than if the interrogator disclosed evidence. That is, we hypothesized that high-NC participants would recognize that consistent evidence obtained independently of the investigators' disclosure of evidence was more damaging to the defendant than evidence that could have been obtained through the investigators' early disclosure.

Third, we did not expect this relationship for low-NC participants. That is, we hypothesized that participants with low-NC would not distinguish between consistent confessions obtained from interrogations using different evidence disclosure techniques.

\section{Study Two Methods}

Design. Similar to study one, we manipulated the consistency of the case facts with the confession by varying the case facts and confession evidence while simultaneously counterbalancing for evidence severity. This study used a 2 (case facts: low vs. high severity) X 2 (confession: low vs. high severity) X 2 (evidence disclosure: disclosed v. withheld) between subjects factorial design. Participants were randomly assigned to one of the eight conditions. 
Similar to study 1 , analyses were conducted with the simplified design of 2 (confession/case facts: consistent v. inconsistent) X 2 (evidence disclosure: disclosed v. withheld). Results from the simplified and full design were the same. NC was included in the model as an independent variable (i.e., an attribute treatment interaction; Caspi \& Bell, 2004).

Participants and Power. Sample size was determined similar to study one. However, we increased the sample size in study two based on recent recommendations on power and factorial analyses, which suggest multiplying a priori sample size estimates by 2, 4, or 14 times depending on the type of interaction effect expected (Giner-Sorolla, 2018). Participants were 1,005 juryeligible U.S. citizens drawn from Amazon's MTurk worker pool. Participants were ineligible to complete study two if they had completed study one, and they were compensated \$3.00. Similar to study one, attention check questions were imbedded throughout the study to gauge participant attention, and participants were excluded for failing any one of the three attention check questions $(N=40)$ or for failing manipulation checks $(N=165$, see below $)$. The analytic sample consisted of the remaining 800 participants, with cell sizes ranging from $N=193$ - 204. Similar to study one, analyses for the full sample are reported in supplemental materials.

The average age for the sample was 39 years old (range $18-77$ years old). The sample was $49.8 \%$ male, $49.4 \%$ female, $0.3 \%$ transgender, and 5 participants "preferred not to answer" or left this question blank. The majority $(61.3 \%)$ of participants had been called for jury duty, and $19.4 \%$ had served in the past. Participants were White $(77.8 \%)$, Black, non-Hispanic (8.5\%), Hispanic (6.6\%), Asian (5.4\%), and other races/ethnicities (1.1\%). 5 participants (0.6\%) did not report their race. Highest obtained education level varied; $10.1 \%$ earned a high school degree, $20.6 \%$ attended some college, $13.9 \%$ earned an associate's degree or technical degree, $38.4 \%$ 
earned a bachelor's degree, $3.6 \%$ attended some graduate school, and $13.0 \%$ earned a graduate degree (3 participants “preferred not to answer” or left this question blank).

Materials. The trial stimulus in study two was the same as the stimulus in study one.

NC scale. We used the revised and shortened 18-item NC scale (Cacioppo, Petty, \& Kao, 1984). Items were rated on a 9-point Likert-type scale ranging from very strong disagreement to very strong agreement. Cronbach’s alpha reliability in this sample was .96 . Similar to past research (e.g., McAuliff \& Kovera, 2008), questions assessing participants’ NC were included during voir dire, before the trial stimulus and questionnaire. We calculated participants' NC by reverse-coding appropriate items and then summing their responses. Scores ranged from 0-144. The mean was 90.89 and median, 95.00. This is consistent with research suggesting MTurk samples have higher NC than other samples (Berinsky, Huber, \& Lenz, 2012). In line with statistical recommendations, $\mathrm{NC}$ was included in the analyses as a continuous variable instead of performing a median split (McClelland, Lynch, Irwin, Spiller, \& Fitzsimons, 2015).

\section{Dependent Variables.}

Verdict, probability of guilt, strength of evidence, reliability of the confession, impression of the interrogation, and defendant ratings. Participants answered verdict, probability of guilt, strength of evidence $(\alpha=.89)$, reliability of the confession $(\alpha=.95)$, impression of the interrogation $(\alpha=.88)$, and defendant rating scales $(\alpha=.97)$ used in study one.

Manipulation check questions. Questions mirrored those in study one. If participants failed any one of the manipulation check questions assessing the presence of the confession, interrogation technique used, and consistency they were excluded (see above, $N=165$ ).

Procedure. Procedure for this study mirrors study one with the addition of the NC scale in the voir dire questionnaire. Participants took on average 21 minutes to complete the study. 


\section{Study Two Results}

To test our hypotheses, we ran a series of regression analyses to assess the effects of the main effects of confession-case facts consistency, evidence disclosure, and NC and the interactions between these variables on our dependent measures. Similar to study one, we expected a main effect of confession-case facts consistency on jurors' decisions. However, we expected this main effect would be qualified by an effect of the three-way interaction between our three variables on our dependent measures in that high NC participants who heard a consistent confession would differentiate between confessions obtained in interrogations in which evidence was disclosed versus withheld. We organized the results by dependent measure given that all analyses were testing the same hypotheses for the various dependent measures.

Effects of case-facts consistency, evidence disclosure, and NC on verdict. In a logistic regression, we examined the effect of the IVs and their interactions on participants' verdict decisions. The overall model was significant, $\chi^{2}(3)=67.61, p<.001$. We found significant main effects of confession-case facts consistency, $B=1.41, S . E=0.21$, Wald's $\chi^{2}=45.62, p<.001$, $\exp (B)=4.10,95 \% C I[2.72,6.18]$; evidence disclosure, $B=0.44, S . E=0.19$, Wald's $\chi^{2}=5.44$ $p=.020, \exp (B)=1.56,95 \% C I[1.07,2.26] ;$ and NC, $B=-0.008, S . E=0.003$, Wald's $\chi^{2}=7.42$, $p=.006, \exp (B)=0.99,95 \% C I[0.99,1.00]$ on verdict.

Participants in consistent confession-case facts conditions were more likely to convict ( $M$ $=30.5 \%)$ than those in inconsistent confession-case facts conditions $(M=9.6 \%)$. Additionally, participants in evidence withheld conditions were more likely to convict $(M=23.33 \%)$ than those in evidence disclosed conditions $(M=16.80 \%)$. Last, higher scores in NC were associated with lower conviction rates. Including interaction terms did not further predict juror verdicts; all other effects were not significant, $p s>0.22$ and are reported in supplemental materials. 
Overview of scalar analyses. To test our hypotheses, we ran a series of linear regression models testing the effect of confession-case facts consistency, evidence disclosure, NC, and the interaction between these variables on our DVs as we hypothesized a significant effect of the interaction that included NC (an attribute treatment interaction) on our DVs. We first mean centered NC. Then, for each measure, we ran a series of linear regressions in which we first included main effects, then added the effect of the 2-way interactions, and then the effect of the three-way interaction on the DV. These regression models were estimated in block format by including main effects in block one, all possible two-way interactions in block two (confessioncase facts consistency X NC; confession-case facts consistency X evidence disclosure, evidence disclosure X NC), and the three-way interaction in block three (confession-case facts consistency X evidence disclosure $\mathrm{X} \mathrm{NC).} \mathrm{We} \mathrm{ran} \mathrm{this} \mathrm{series} \mathrm{of} \mathrm{models} \mathrm{to} \mathrm{determine} \mathrm{which} \mathrm{model} \mathrm{was}$ significant (and thereby best explained the effect of our IVs on the DV), although for all DVs we expected an effect of the three-way interaction based on our hypotheses. See Tables 4-8 for a report of all blocks of these linear regression models; significant main effects and interactions effects are starred for emphasis. We report significant main effects if they were not qualified by a higher order interaction. For significant effects, we report post-hoc analyses using post-hoc ANOVAs for continuous measures; post-hoc analyses are organized by DV.

\section{Effects of case-facts consistency, evidence disclosure, and NC on probability of guilt}

ratings. Table 4 shows results examining the effects of our IVs and their interactions on probability of guilt ratings. Examining these results, participants in consistent confession-case facts conditions rated the defendants' probability of guilt higher than those in inconsistent conditions, $M_{\text {consistent }}=47.33, S D=30.41, S E=1.38, M_{\text {inconsistent }}=26.50, S D=25.29, S E=1.40$, $d=0.74,95 \% C I[0.60,0.89]$. Participants in evidence withheld conditions rated the defendants' 
probability of guilt higher than those in evidence disclosed conditions, $M_{\text {withheld }}=39.65, S D=$ 30.94, $S E=1.38, M_{\text {disclosed }}=34.19, S D=28.50, S E=1.40, d=0.18,95 \% C I[0.04,0.32]$. Last, higher scores in $\mathrm{NC}$ were associated with lower probability of guilt ratings.

\section{Effects of case-facts consistency, evidence disclosure, and NC on strength of evidence}

ratings. Table 5 shows results examining the effects of our IVs and their interactions on strength of evidence. Examining these results, first, higher scores in NC were associated with lower strength of evidence ratings. Examining the interaction between confession-case facts consistency and evidence disclosure, there was a simple main effect of evidence disclosure within consistent conditions, $p<0.001$. In conditions in which the confession and case facts were consistent, participants in evidence withheld conditions rated the strength of evidence stronger than those in evidence disclosed conditions, $M_{\text {withheld }}=3.31, S D=1.14, S E=0.07$, $M_{\text {disclosed }}=2.94, S D=1.05, S E=0.07, d=0.34,95 \% C I[0.14,0.53]$. The effect of evidence disclosure was not significant within inconsistent confession-case facts conditions, $p=0.59$, $M_{\text {withheld }}=2.44, S D=0.96, S E=0.07, M_{\text {disclosed }}=2.38, S D=0.92, S E=0.07, d=0.06,95 \%$ CI $[-$ $0.13,0.26]$. See Figure 1.

\section{Effects of case-facts consistency, evidence disclosure, and NC on reliability of the}

confession ratings. Table 6 shows results examining the effects of our IVs and their interactions on reliability of the confession ratings. Examining these results, first, higher scores in NC were associated with lower reliability of the confession ratings. Examining the interaction between consistency and evidence disclosure, there was a simple main effect of evidence disclosure within consistent confession-case facts conditions, $p<0.001$. When the confession and case facts were consistent, participants in evidence withheld conditions rated the reliability of the confession higher than those in evidence disclosed conditions, $M_{\text {withheld }}=3.32, S D=1.41, S E=$ 
$0.09, M_{\text {disclosed }}=2.79, S D=1.39, S E=0.09, d=0.38,95 \% C I[0.18,0.58]$. The effect of evidence disclosure was not significant within inconsistent confession-case facts conditions, $p=$ 0.91, $M_{\text {withheld }}=2.22, S D=1.00, S E=0.09, M_{\text {disclosed }}=2.23, S D=0.96, S E=0.09, d=-0.01$, 95\% CI [-0.21, 0.19]. See Figure 1.

\section{Effects of case-facts consistency, evidence disclosure, and NC on impression of the}

interrogation ratings. Table 7 shows results examining the effects of our IVs and their interactions on impression of the interrogation ratings. Examining these results, higher scores in $\mathrm{NC}$ were associated with lower (more negative) impressions of the interrogation ratings.

Examining the interaction between consistency and evidence disclosure, there was a simple main effect of evidence disclosure within consistent confession-case facts conditions, $p<0.001$. In conditions in which the confession and case facts were consistent, participants in evidence withheld conditions had a more positive impression of the interrogation than those in evidence disclosed conditions, $M_{\text {withheld }}=3.16, S D=1.30, S E=0.08, M_{\text {disclosed }}=2.34, S D=1.24, S E=$ $0.08, d=0.65,95 \% C I[0.44,0.85]$. This effect was not significant within inconsistent confession-case facts conditions, $p=0.075, M_{\text {withheld }}=2.25, S D=0.93, S E=0.08, M_{\text {disclosed }}=$ 2.05, $S D=0.97, S E=0.08, d=0.21,95 \% C I[0.01,0.41]$. See Figure 1.

\section{Effects of case-facts consistency, evidence disclosure, and NC on ratings of the}

defendant's character. Table 8 shows results examining the effects of our IVs and their interactions on ratings of the defendant's character. Examining these results, participants in inconsistent confession-case facts conditions rated the defendant more positively than those in consistent conditions, $M_{\text {inconsistent }}=4.19, S D=1.08, S E=0.06, M_{\text {consistent }}=3.59, S D=1.14, S E=$ $0.06, d=0.54,95 \% C I[0.40,0.68]$. Participants in evidence disclosed conditions rated the defendant more positively than those in evidence withheld conditions, $M_{\text {disclosed }}=3.98, S D=$ 
$1.08, S E=0.06, M_{\text {withheld }}=3.80, S D=1.21, S E=0.06, d=0.16,95 \% C I[0.02,0.30]$. And, higher scores in NC were associated with more positive evaluations of the defendant's character.

\section{Study Two Discussion}

In this study, participants were more likely to convict in consistent confession-case facts conditions than inconsistent conditions. Additionally, we found main effects of evidence disclosure and NC on participants' verdicts; participants were more likely to convict if evidence was withheld compared to disclosed, and participants higher in NC were less likely to convict than those lower in NC. Consistent with study one, there was a main effect of confession-case facts consistency on probability of guilt ratings; participants in consistent conditions averaged probability of guilt ratings 20.24 points higher than those in inconsistent conditions.

We found the expected interaction effect between confession-case facts consistency and evidence disclosure on participants' ratings of the strength of evidence, reliability of the confession, and impression of the interrogation. Participants who heard a consistent confession in evidence withheld conditions rated the strength of evidence and reliability of the confession higher than those evidence disclosed conditions. This suggests that participants assigned stronger weight to a consistent confession that was obtained through an interrogation where evidence was withheld rather than disclosed, where the defendant could have been made privy to consistent details through the interrogation process.

In consistent case facts-confession conditions, participants rated their overall impression of the interrogation more positively in evidence withheld conditions compared to evidence disclosed conditions. Additionally, participants rated the defendant's character higher (more positively) in inconsistent confession-case facts conditions compared to consistent conditions, higher in evidence disclosed conditions compared to evidence withheld conditions, and higher 
amongst participants higher in NC compared to those lower in NC. Thus, in study two, we detected significant interaction effects on many dependent measures, whereas in study one we hypothesized these relationships but did not see them in the results (aside from ratings of the defendant). It is possible that despite the power analysis we conducted prior to study one, we did not have enough power to detect the interaction effects proposed, which might help to explain the differences between study one and study two.

\section{Summary and Discussion}

In these studies, we explored the effect of confession-case facts consistency and evidence disclosure on participants' evaluations of confession evidence. Consistent with past research (Alceste et al., 2019, study one; Henderson \& Levett, 2016), we found that confession-case facts consistency influenced participants' verdicts (in study two). Participants were more likely to convict when the confession details and case facts were consistent compared to inconsistent. While there was also a main effect of evidence disclosure on participants' verdicts in study two, this effect did not interact with confession-case facts consistency to affect verdict in either study. Overall, participants are using consistency as a cue to accuracy, but this comes with concern, as they did not consider the possibility of whether the confession information was the result of interrogation techniques in assigning culpability or rendering verdicts. Other research has shown that jurors can be sensitive to the origin of confession information in rendering a verdict (Alceste et al., 2019, study two); however, our studies did not show sensitivity on the verdict measure.

In study two, using a different guideline to calculate our a priori sample size, we found significant effects of the interaction between confession-case facts consistency and evidence disclosure on many dependent measures, indicating that perhaps more power is needed to see the effect of the interaction. Generally, continuous measures in mock jury research may be more 
sensitive to variations in evidence quality than verdict (e.g., Shaked-Schroer et al., 2015), and the observations in study two show that general pattern. In confession-case facts consistent conditions, participants perceived the confession evidence as more reliable and assigned it more weight when it was obtained through an interrogation in which evidence was withheld compared to disclosed. As expected, the effect of evidence disclosure was not significant in inconsistent conditions. That is, when interrogators disclose evidence to suspects during the interrogation, it contaminates any subsequent confession, making it difficult for jurors to properly evaluate that evidence, regardless of consistency. Instead, when interrogators withhold evidence, strategically using it in the interrogation, it allows fact-finders to differentiate between a more or less reliable confession, using consistency. In study two, we found that participants viewed a consistent confession obtained using best practices (evidence withheld) as more reliable compared to a consistent confession obtained using more traditional techniques (evidence disclosed).

Participants were also sensitive to the benefits of withholding evidence during the interrogation in their overall impression of the interrogation ratings. In evaluating the interrogation, when the confession and case facts were consistent, participants who heard interrogators withheld evidence had higher overall ratings of the interrogation than participants who heard evidence was disclosed. This effect was not significant in inconsistent conditions. This is supportive of our hypotheses; inconsistency isn't a tool to accuracy, and consistency is only valid when interrogators withheld evidence during the interrogation.

Furthermore, in study one, we found a significant interaction between confession-case facts consistency and evidence disclosure on participants' ratings of the defendant. If participants read that the interrogator withheld evidence during the interrogation, they rated the defendant more positively when his confession was inconsistent compared to consistent (this effect was not 
significant in evidence disclosed conditions). That is, if the interrogator withheld evidence from the suspect, but yet the defendant's subsequent confession was inconsistent (less reliable), that defendant was perceived as more credible, honest, trustworthy, etc. than a defendant whose confession was consistent (more reliable).

\section{Implications for Theory: Systematic v. Heuristic Processing of Confession Evidence}

In study one, we did not find strong support for a sensitivity effect in that participants were not attuned to the possible origin of consistent confession information. In only one measure, ratings of the defendant's character, did participants make the connection between evidence disclosure techniques and confession content. In study two, we sought to examine if individual differences, NC, moderate jurors' sensitivity. Following the Dual Process Models of Persuasion (Petty \& Wegener, 1998), we expected that those participants higher in NC would be high in ability and motivation to detect variations in the confession evidence (i.e., notice in which evidence disclosure conditions consistency is an indicator of reliability). That is, these individuals would be using the systematic or central route to persuasion to reach a decision. We expected that low NC participants would not be sensitive to variations in the quality of the confession evidence, and instead, follow the heuristic or peripheral route to persuasion.

However, instead of the expected interaction effect, we found main effects of NC on most measures. Participants higher in NC were less likely to convict, and rated the defendant's probability of guilt, strength of evidence, and reliability of the confession lower than participants lower in NC. Thus, participants higher in NC seemed more skeptical of the trial overall, and they were no more sensitive to variations in evidence than participants lower in NC.

Instead, across these studies (although not consistently), we found some evidence that participants were sensitive to variations in confession evidence and evidence disclosure without 
accounting for NC. While reassuring, this sensitivity did not translate to verdicts, arguably the most important and ecologically valid outcome at trial. In this study, participants could have been following the heuristic route to persuasion in their verdict decisions, which is why we saw no variation in conviction rates across more or less reliable confession evidence. This would be consistent with other research pointing to the damaging effects of confession evidence, regardless of threats to reliability (e.g., Shaked-Schroer et al., 2015). That is, jurors could have been motivated in their verdict decisions by the presence of the confession evidence or what they perceived to be an indicator of accuracy- consistency (using the heuristic route). Heuristic and systematic processing can occur simultaneously, and it is possible that jurors were able to systematically process the confession evidence in evaluating evidence generally, but were more likely to use heuristics in rendering a verdict. Therefore, it is possible that all jurors, regardless of $\mathrm{NC}$, could benefit from legal safeguards such as expert testimony, to help bridge the gap between evaluation of evidence and verdict decisions (process information using the systematic route).

\section{Implications for Practice: Accusatorial Interrogation Techniques}

Accusatorial interrogations, common to the United States, increase the risk of a false confession (Perillo \& Kassin, 2011; Russano, Meissner, Narchet, \& Kassin, 2005). Coupled with research suggesting jurors are not sensitive to these coercive interrogation techniques in their evaluation of confession evidence (Jones \& Penrod, 2016) nor their verdict decisions (ShakedSchroer et al., 2015), highlights the dangers of these techniques, and that confessions elicited from them should be viewed with caution. These data speak to that concern on the key dependent variable- verdict. These data further contribute to that body of research. Participants did not differ in their conviction rates between a suspect whose confession was consistent, but evidence withheld, and one whose confession was consistent, but evidence disclosed. That is, jurors were 
not sensitive to evidence contamination in rendering verdicts.

However, participants were sensitive to evidence contamination on most of our other dependent variables- strength of evidence, reliability of the confession, impression of the interrogation (study 2), and ratings of the defendant (study 1). From a practice perspective, this suggests participants are cognizant of threats to the reliability of confession evidence, and that translates to the evidentiary weight assigned and evaluations of the interrogation and defendant. This differs from past work (Jones \& Penrod, 2016), where participants did not distinguish between differing types of interrogation techniques in rating the confession. Instead, these data suggest jurors are somewhat attuned to threats to reliability of the confession evidence, and look to the techniques used to obtain that admission in their decision-making. And while this did not translate to ultimate verdicts in our study, jurors' assigning more weight to a consistent confession, where evidentiary information was not shared, is promising from a practice standpoint. As suggested (Hartwig et al., 2006), withholding evidence during the interrogation allowed jurors to critically evaluate the content of the confession evidence. However, given that this evaluation did not translate to participants' decisions on verdict, policies in the interrogation room should follow best practices regarding preserving case information, ensuring that suspects' statements are not contaminated.

\section{Limitations and Future Directions}

These studies are not without limitations. First, although the MTurk sample is arguably more ecologically valid than an undergraduate student sample, participants were participating online, which limits the overall ecological validity of the paradigm. We were also unable to control whether MTurk participants completed the study without aid from others, although they 
were instructed to do so. Future research should examine whether these results replicate with more ecological valid samples that address these issues (e.g., jurors reporting for jury duty).

We did not inquire about prior interactions with the police or a criminal record, which may have affected participants' decisions. We also did not include questions asking participants about their perceptions of the purpose of the studies. While we minimized the chances participants would guess the manipulations of our study by presenting them within the context of the full trial, it is a limitation that we do not have data to support that assertion.

Second, the stimulus used in these two studies was the same; future research should attempt to replicate and extend the effects using a different stimulus to ensure generalizability across many types of cases. It is also possible that the nuances of this particular case influenced results. That is, if participants perceived the evidence in this case to be particularly weak, they may not have been as sensitive to the manipulations. Future research could manipulate the strength of the case more directly to assess whether the strength of the evidence interacts with the manipulations in this study to affect jurors' decisions.

Another shortcoming of our stimulus is that it was a written trial rather than a videotaped stimulus. While we presented a full trial as to not focus participants on just confession evidence (thereby giving away the purpose of the study), a more ecologically valid stimulus would have presented the full videotaped trial. In some jurisdictions, jurors may view a video of the interrogation and/or confession. It is possible that viewing the video of the interrogation and/or confession may make the variables we investigated more salient, given the jurors would be witnessing the interactions rather than reading testimony about them. However, it is also possible that the manipulations would be less salient given the amount of information typically included in these types of videos. Future research should examine these questions. 
Third, it is possible that other factors may influence how well jurors process information about the consistency of confession evidence and case facts (and the origin of the consistent or inconsistent information). For example, past research showed that expert testimony has promise for educating jurors about such inconsistencies (Henderson \& Levett, 2016). Future research could examine the effectiveness of expert testimony or other educative mechanisms (educational cross examination, jury instructions) in educating jurors about the consistency of confession evidence and case facts and the origins of that information.

\section{Conclusion}

Jurors evaluate a confession containing details as more reliable than a confession without such level of detail (Appleby et al., 2013). This is concerning considering that false confessions can contain consistent details, details that were provided to the suspect during the interrogation (Garrett, 2010). A consistent confession can only be considered a high-quality piece of evidence if the interrogation followed best practices; one such practice is withholding evidence. In this study, participants were sensitive to the consistency of confession details with other case facts across most measures. Furthermore, on some measures, participants were attuned to the possible source of consistent information (interrogation v. suspect). Participants perceived a consistent confession obtained using best practices (i.e., evidence withheld) as a stronger and more reliable piece of evidence than a consistent confession obtained using traditional practices (i.e., evidence disclosed). However, this effect was not significant for verdict decisions, suggesting that jurors are swayed by a confession, even if that confession has been potentially contaminated during the interrogation process. 


\section{References}

Alceste, F., Crozier, W.E., Strange, D. (2019). Contaminated confessions: How source and consistency of confession details influence memory and attributions. Journal of Applied Research in Memory and Cognition, 8, 78-91. https://doi.org/10.1016/j.jarmac.2018.08.005

Appleby, S., Hasel, L., \& Kassin, S. (2013). Police-induced confessions: An empirical analysis of their content and impact. Psychology, Crime \& Law, 19, 111-128. http://dx.doi.org/10.1080/1068316X.2011.613389

Berinsky, A. J., Huber, G. A., \& Lenz, G. S. (2012). Evaluating online labor markets for experimental research: Amazon.com's mechanical turk. Political Analysis, 20(3), 351368. doi:10.1093/pan/mpr057

Bornstein, B. H. (2004). The impact of different types of expert scientific testimony on mock jurors' liability verdicts. Psychology, Crime, and Law, 10, 429-446. http://dx.doi.org/10.1080/1068316030001629292

https://www.ca6.uscourts.gov/pattern-jury-instructions

Cacioppo, J. T., \& Petty, R. E. (1982). The need for cognition. Journal of Personality and Social Psychology, 42(1), 116-131. http://dx.doi.org/10.1037/0022-3514.42.1.116

Cacioppo, J. T., Petty, R. E., \& Kao, C. F. (1984). The efficient assessment of need for cognition. Journal of Personality Assessment, 48, 306-307. https://doi.org/10.1207/s15327752jpa4803_13

Cacioppo, J. T., Petty, R. E., Kao, C. F., \& Rodriguez, R. (1986). Central and peripheral routes to persuasion: An individual difference perspective. Journal of Personality and Social Psychology, 51, 1032-1043. http://psycnet.apa.org/doi/10.1037/0022-3514.51.5.1032 
Caspi, O. \& Bell, I. R. (2004). One Size Does Not Fit All: Aptitude x treatment interaction (ATI) as a conceptual framework for complementary and alternative medicine outcome research. Part 1-what is ATI research? The Journal of Alternative and Complementary Medicine, 10(3), 580-586.

Chaiken, S., Liberman, A., \& Eagly, A. (1989). Heuristic and systematic information processing within and beyond the persuasion context. In J. S. Uleman \& J. A. Bargh (Eds.), Unintended thought (pp. 212-251). New York: Guilford Press.

Cohen, J. (1988). Statistical power analysis for the behavioral sciences (2nd ed.). New Jersey: Lawrence Erlbaum.

DNA Exonerations in the United States (n.d.). Innocence Project. Retrieved February 12, 2020 from https://www.innocenceproject.org/dna-exonerations-in-the-united-states/

Drizin, S., Nirider, L., Nawoichyk, J., \& Tepfer, J. (2012). Reducing risks: An executive’s guide to effective juvenile interview and interrogation. retrieved from http://www.theiacp.org/Portals/0/pdfs/ReducingRisksAnExecutiveGuidetoEffectiveJuven ileInterviewandInterrogation.pdf

Faul, F., Erdfelder, E., Lang, A.-G., \& Buchner, A. (2007). G_Power 3: A flexible statistical power analysis program for the social, behavioral, and biomedical sciences. Behavior Research Methods, 39, 175-191. http://dx.doi.org/10.3758/BF03193146

Garrett, B. (2010). The substance of false confessions. The Stanford Law Review, 62, 10511119. Retrieved from http://www.stanfordlawreview.org/wpcontent/uploads/sites/3/2010/04/Garrett.pdf

Giner-Sorolla, R. (2018, January 24). Powering your interaction [blog post]. Retrieved from https://approachingblog.wordpress.com/2018/01/24/powering-your-interaction-2/ 
Gudjonsson, G. H., \& Pearse, J. (2011). Suspect interviews and false confessions. Current Directions in Psychological Science, 20(1), 33-37. doi:10.1177/0963721410396824

Hartwig, M., Granhag, P., Stromwall, L., \& Kronkvist, O. (2006). Strategic use of evidence during police interviews: When training to detect deception works. Law and Human Behavior, 30(5), 603-619. doi:10.1007/s10979-006-9053-9

Hartwig, M., Granhag, P. A., Stromwall, L. A., \& Vrij, A. (2005). Detecting deception via strategic disclosure of evidence. Law and Human Behavior, 29, 469-484. https://doi.org/10.1007/s10979-005-5521-X

Haugtvedt, C.P., Petty, R.E., \& Cacioppo, J.T. (1992). Need for cognition and advertising: Understanding the role of personality variables in consumer behavior. Journal of Consumer Psychology, 1(3), 239-260. https://doi.org/10.1016/S1057-7408(08)80038-1

Henderson, K. S., \& Levett, L. M. (2016). Can expert testimony sensitize jurors to variations in confession evidence? Law and Human Behavior, 40(6), 638-649. http://dx.doi.org/10.1037/lhb0000204

Inbau, F. E., Reid, J. E., Buckley, J. P. (1986). Criminal interrogation and confessions ( $3^{\text {rd }}$ ed.). Baltimore, MD: Williams \& Wilkins.

Jones, A.M. \& Penrod, S. (2016) Can expert testimony sensitize jurors to coercive interrogation tactics? Journal of Forensic Psychology Practice, 16(5), 393-409. DOI: $10.1080 / 15228932.2016 .1232029$

https://www.innocenceproject.org/causes/false-confessions-admissions/

Kassin, S. M. (2005). On the psychology of confessions: Does innocence put innocents at risk? American Psychologist, 60, 215-228. https://doi.org/10.1037/0003-066X.60.3.215 
Kassin, S. M., Drizin, S. A., Grisso, T., Gudjonsson, G. H., Leo, R. A., \& Redlich, A. D. (2010). Police-induced confessions: Risk factors and recommendations. Law and Human Behavior, 34(1), 3-38. doi:10.1007/s10979-009-9188-6

Kassin, S. M., \& Gudjonsson, G. H. (2004). The psychology of confessions: A review of the literature and issues. Psychological Science in the Public Interest, 5, 33-67. 10.1111/j.1529-1006.2004.00016.x

Kassin, S.M., Leo, R.A., Meissner, C.A., Richman, K.D., Colwell, L.H., Leach, A., \& La Fon, D. (2007). Police interviewing and interrogation: A self-report survey of police practices and beliefs. Law and Human Behavior, 31, 381-400. doi: 10.1007/s10979-006-9073-5

Kassin, S. M., \& Neumann, K. (1997). On the power of confession evidence: An experimental test of the fundamental difference hypothesis. Law and Human Behavior, 21, 469-484. http://dx.doi.org/10.1023/A:1024871622490

Kassin, S.M., \& Sukel, H. (1997). Coerced confessions and the jury: An experimental test of the "harmless error" rule. Law and Human Behavior, 21(1), 27-46. doi: 10.1023/A:1024814009769

Kelly, C. E., Miller, J. C., Redlich, A. D., \& Kleinman, S. M. (2013). A taxonomy of interrogation methods. Psychology, Public Policy, and Law, 19(2), 165-178. doi:http://dx.doi.org.proxy.lib.pdx.edu/10.1037/a0030310

King, L. \& Snook, B. (2009). Peering inside a Canadian interrogation room: An examination of the Reid model of interrogation, influence tactics, and coercive strategies. Criminal Justice \& Behavior, 36(7), 674-694. DOI: 10.1177/0093854809335142

Leo, R. A. (1996). Inside the interrogation room. Journal of Criminal Law and Criminology, 86, 266-303. doi: 10.2307/1144028 
Leo, R. (2009). False confessions: Causes, consequences, and implications. Journal of the American Academy of Psychiatry and the Law, 37(3) 332-343. Retrieved from http://jaapl.org/content/37/3/332

Leo, R. A., \& Ofshe, R. J. (1998). The consequences of false confession: Deprivations of liberty and miscarriages of justice in the age of psychological interrogation. Journal of Criminal Law and Criminology, 88, 429-496. doi:10.2307/1144288

Levett, L., \& Kovera, M. (2008). The effectiveness of opposing expert witnesses for educating jurors about unreliable expert evidence. Law and Human Behavior, 32(4), 363-374. doi:10.1007/s10979-007-9113-9

McAuliff, B.D. \& Kovera, M.B. (2008). Juror need for cognition and sensitivity to methodological flaws in expert evidence. Journal of Applied Social Psychology, 38(2), 385-408. doi:10.1111/j.1559-1816.2007.00310.x

McClelland, G.H., Lynch, J.G., Irwin, J.R., Spiller, S.A., \& Fitzsimons, G.J. (2015). Median splits, type II errors, and false-positive consumer psychology: Don't fight the power. Journal of Consumer Psychology, 25(4), 679-689. https://doi.org/10.1016/j.jcps.2015.05.006

Meissner, C.A., Redlich, A.D., Michael, S.W., Evans, J.R., Camilletti, C.R., Bhatt, S., \& Brandon, S. (2014). Accusatorial and information-gathering interrogation methods and their effects on true and false confessions: a meta-analytic review. Journal of Experimental Criminology, 10, 459-486. DOI 10.1007/s11292-014-9207-6

Miranda v. Arizona, 384 U.S. 436 (1966) 
Palmer, M.A., Button L., Barnett, E., \& Brewer, N. (2016). Inconsistencies undermine the credibility of confession evidence. Legal and Criminological Psychology, 21, 161-173. DOI:10.1111/lcrp.12048

Perillo, J. T., \& Kassin, S. M. (2011). Inside interrogation: The lie, the bluff, and false confessions. Law and Human Behavior, 35(4), 327-337. doi:10.1007/s10979-0109244-2

Petty, R. E., \& Cacioppo, J. T. (1986). The elaboration likelihood model of persuasion. In L. Berkowitz (Ed.), Advances in experimental social psychology (p. 123-203). New York: Academic Press.

Petty, R. E., \& Wegener, D. T. (1998) Attitude change: Multiple roles for persuasion variables. In D. T. Gilbert, S. T. Fiske, \& G. Lindzey (Eds.), The Handbook of social psychology (p. 323-390). Boston: McGraw-Hill

Russano, M. B., Meissner, C. A., Narchet, F. M., \& Kassin, S. M. (2005). Investigating true and false confession within a novel experimental paradigm. Psychological Science, 16, 481486. doi:10.1111/j.0956-7976.2005.01560.x

Shaked-Schroer, N., Costanzo, M. \& Berger, D. E. (2015). Overlooking coerciveness: The impact of interrogation techniques and guilt corroboration on jurors' judgments of coerciveness. Legal and Criminological Psychology, 20, 68-80. doi:10.1111/lcrp.12011

Sheehan, K. B. (2018) Crowdsourcing research: Data collection with Amazon's Mechanical Turk, Communication Monographs, 85(1), 140-156. doi: 10.1080/03637751.2017.1342043

Sixth Circuit Committee (2019, July 1). Pattern Criminal Jury Instructions. United States Court of Appeals for the Sixth Circuit. Retrieved from https://www.ca6.uscourts.gov/patternjury-instructions 
Sommers, S.R. \& Kassin, S.M. (2001). On the many impacts of inadmissible testimony:

Selective compliance, need for cognition, and the overcorrection bias. Personality and Social Psychology Bulletin, 27(10), 1368 - 1377.

https://doi.org/10.1177/01461672012710012

Washington v. Commonwealth, 228 Va. 535, 323 S.E.2d 577 (1984)

Woestehoff, S. A., \& Meissner, C. A. (2016). Juror sensitivity to false confession risk factors:

Dispositional vs. situational attributions for a confession. Law and Human

Behavior, 40(5), 564-579. doi:http://dx.doi.org.proxy.lib.pdx.edu/10.1037/lhb0000201 
Figure 1

Study Two: Interaction Effect of Evidence Disclosure and Consistency of Confession and Case-

Facts on Participants' Strength of Evidence (Evidence), Reliability of the Confession

(Confession), and Impression of the Interrogation (Interrogation) Ratings
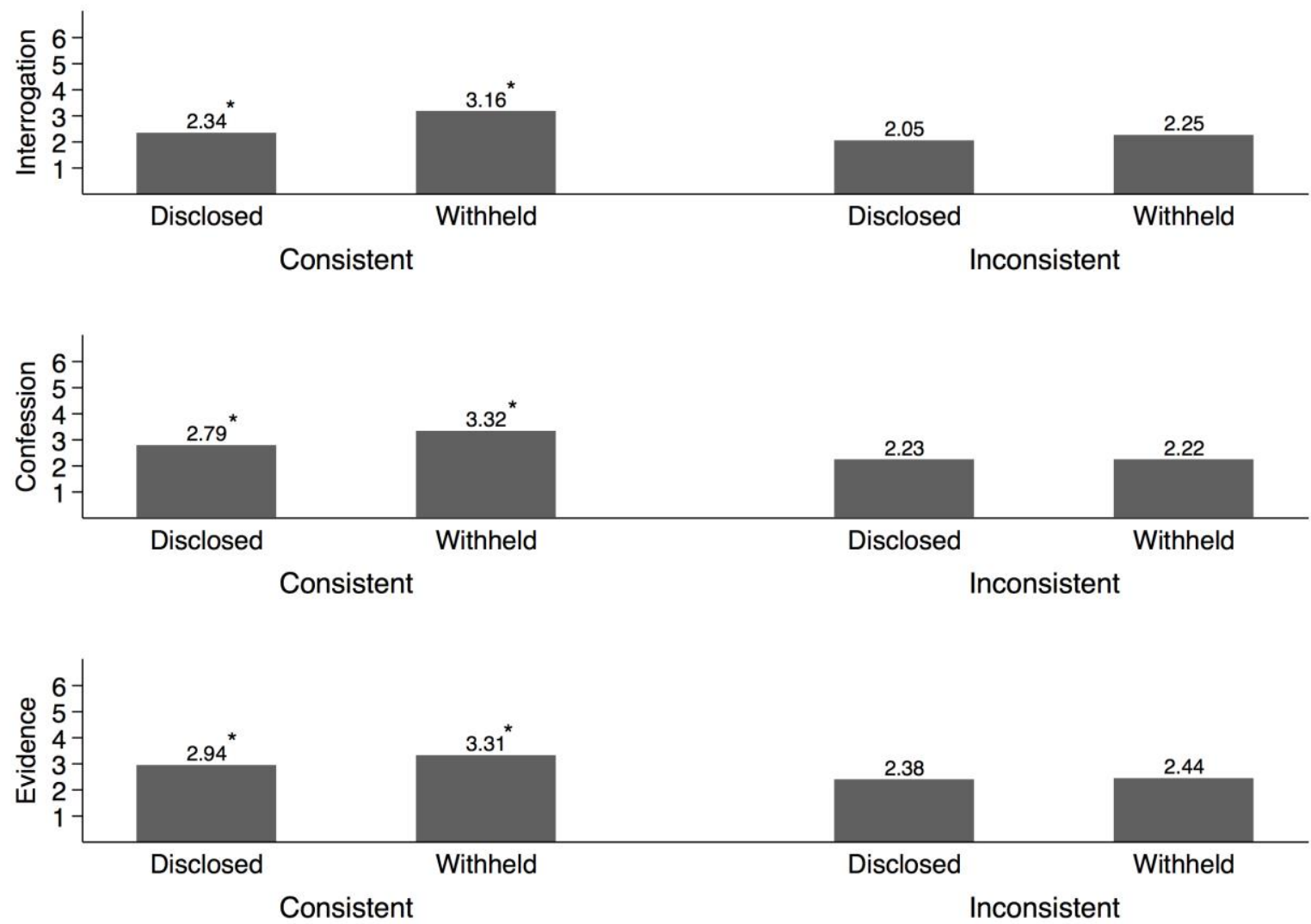

Note. $* p<.05$. 
Table 1

Scale Items and Alpha Reliability Scores

\begin{tabular}{|c|c|c|}
\hline Scale & Items & Alpha $\alpha$ \\
\hline $\begin{array}{l}\text { Strength of } \\
\text { evidence }\end{array}$ & $\begin{array}{l}\text { The evidence presented by the prosecution was convincing. } \\
\text { The defense had a very strong case }(\mathrm{R}) \text {. } \\
\text { The evidence presented by the prosecution was not very } \\
\text { persuasive }(\mathrm{R}) \text {. } \\
\text { The evidence presented by the defense was convincing (R). } \\
\text { The evidence presented by the defense was not very } \\
\text { persuasive. } \\
\text { The prosecution had a very strong case. }\end{array}$ & 0.91 \\
\hline $\begin{array}{l}\text { Reliability of } \\
\text { the } \\
\text { confession }\end{array}$ & $\begin{array}{l}\text { The suspect's confession is the strongest piece of evidence. } \\
\text { The suspect's confession was not the strongest piece of } \\
\text { evidence (R). } \\
\text { The confession in this case proved the suspect committed } \\
\text { the crime. } \\
\text { The confession in this case did not prove the suspect } \\
\text { committed the crime (R). } \\
\text { The confession evidence in this case is very reliable. } \\
\text { The confession evidence in this case is not reliable (R). } \\
\text { Because the suspect confessed, I would not be able to } \\
\text { acquit. } \\
\text { I believe the suspect in this case actually committed the } \\
\text { crime because he confessed. }\end{array}$ & 0.95 \\
\hline $\begin{array}{l}\text { Overall } \\
\text { impression } \\
\text { of the } \\
\text { interrogation }\end{array}$ & $\begin{array}{l}\text { The interrogation technique could have led to a false } \\
\text { confession }(\mathrm{R}) \text {. } \\
\text { The interrogation was conducted well. } \\
\text { The interrogation technique could not have led to a false } \\
\text { confession. } \\
\text { The interrogation was not conducted well (R). }\end{array}$ & 0.88 \\
\hline
\end{tabular}

Note. (R) denotes that item was reverse coded. 
Table 2

Study One: Means, (Standard Deviations), Standard Errors, and [95\% Confidence Intervals], for Dependent Measures as a Function of the Effect of Confession-Case Facts Consistency

Univariate effect of confession-case facts consistency

\begin{tabular}{|c|c|c|c|c|c|c|}
\hline Measure & Consistent & Inconsistent & $F$ & $d f$ & $p$ & $d[95 \% \mathrm{CI}]$ \\
\hline Probability & $46.01 *(32.19)$ & $27.83(26.38)$ & 27.84 & $(1,280)$ & $p<.001$ & 0.62 \\
\hline \multirow[t]{2}{*}{ of guilt } & 2.56 & 2.30 & & & & {$[0.38,0.86]$} \\
\hline & {$[40.96,51.05]$} & {$[23.29,32.36]$} & & & & \\
\hline Strength of & $3.22 *(1.23)$ & $2.49(1.01)$ & 30.22 & $(1,280)$ & $p<.001$ & 0.66 \\
\hline \multirow[t]{2}{*}{ evidence } & 0.10 & 0.09 & & & & {$[0.41,0.90]$} \\
\hline & {$[3.03,3.41]$} & {$[2.32,2.67]$} & & & & \\
\hline Reliability of & $3.01 *(1.47)$ & $2.32(1.06)$ & 21.01 & $(1,280)$ & $p<.001$ & 0.55 \\
\hline \multirow[t]{2}{*}{ confession } & 0.11 & 0.10 & & & & {$[0.31,0.78]$} \\
\hline & {$[2.79,3.23]$} & {$[2.12,2.52]$} & & & & \\
\hline Impression & $2.84 *(1.44)$ & $2.23(1.04)$ & 18.00 & $(1,282)$ & $p<.001$ & 0.49 \\
\hline of & 0.11 & 0.10 & & & & {$[0.26,0.73]$} \\
\hline interrogation & {$[2.63,3.05]$} & {$[2.04,2.42]$} & & & & \\
\hline Character of & $3.64 *(1.21)$ & $3.93(1.13)$ & 4.28 & $(1,280)$ & $p=.040$ & -0.25 \\
\hline \multirow[t]{2}{*}{ defendant } & 0.10 & 0.09 & & & & {$[-0.48,-0.01]$} \\
\hline & {$[3.44,3.84]$} & {$[3.74,4.11]$} & & & & \\
\hline
\end{tabular}

Note. CIs are in brackets. Probability of guilt scale, 0-100\%. All others, 6-point Likert-type scales with 1 indicating strongly disagree and 6 indicating strongly agree. $* p<.05$. 
Table 3

Study One: Means, (Standard Deviations), Standard Errors, and [95\% Confidence Intervals], for Dependent Measures as a Function of the Effect of Evidence Disclosure

Univariate effect of evidence disclosure

\begin{tabular}{|c|c|c|c|c|c|c|}
\hline Measure & Withheld & Disclosed & $F$ & $d f$ & $p$ & $d[95 \% \mathrm{CI}]$ \\
\hline Probability & $40.76(32.74)$ & $33.07(27.50)$ & 4.97 & $(1,280)$ & $p=.027^{\mathrm{ns}}$ & 0.25 \\
\hline \multirow[t]{2}{*}{ of guilt } & 2.39 & 2.48 & & & & {$[0.02,0.49]$} \\
\hline & {$[36.06,45.46]$} & {$[28.18,37.96]$} & & & & \\
\hline Strength of & $2.93(1.25)$ & $2.78(1.07)$ & 1.34 & $(1,280)$ & $p=.248$ & 0.13 \\
\hline \multirow[t]{2}{*}{ evidence } & 0.09 & 0.10 & & & & {$[-0.10,0.36]$} \\
\hline & {$[2.75,3.11]$} & {$[2.59,2.97]$} & & & & \\
\hline Reliability of & $2.78(1.40)$ & $2.56(1.21)$ & 2.14 & $(1,280)$ & $p=.144$ & 0.17 \\
\hline \multirow[t]{2}{*}{ confession } & 0.11 & 0.11 & & & & {$[-0.07,0.40]$} \\
\hline & {$[2.57,2.98]$} & {$[2.35,2.77]$} & & & & \\
\hline Impression & $2.81 *(1.29)$ & $2.26(1.20)$ & 14.34 & $(1,282)$ & $p<.001$ & 0.44 \\
\hline of & 0.10 & 0.10 & & & & {$[0.21,0.68]$} \\
\hline interrogation & {$[2.61,3.01]$} & {$[2.06,2.47]$} & & & & \\
\hline Character of & $3.60 *(1.15)$ & $3.97(1.17)$ & 7.50 & $(1,280)$ & $p=.007$ & -0.32 \\
\hline \multirow[t]{2}{*}{ defendant } & 0.10 & 0.10 & & & & {$[-0.55,-0.08]$} \\
\hline & {$[3.41,3.78]$} & {$[3.78,4.16]$} & & & & \\
\hline
\end{tabular}

Note. CIs are in brackets. Probability of guilt scale, 0-100\%. All others, 6-point Likert-type scales with 1 indicating strongly disagree and 6 indicating strongly agree. ${ }^{*} p<.05 .{ }^{\mathrm{ns}}=$ not significant at multivariate level. 
Table 4

Study Two: Effects of Evidence Disclosure (Ev), Consistency of Confession and Case-Facts (Consis) and NC on Participants' Probability of Guilt Ratings

\begin{tabular}{|c|c|c|c|c|c|c|c|c|c|}
\hline \multirow[t]{2}{*}{ IV/Model } & \multicolumn{3}{|c|}{ Block 1} & \multicolumn{3}{|c|}{ Block 2} & \multicolumn{3}{|c|}{ Block 3} \\
\hline & $B[95 \% C I$ of $B]$ & $S E$ & $p$ & $B[95 \% C I$ of $B]$ & $S E$ & $p$ & $B[95 \% C I$ of $B]$ & $S E$ & $p$ \\
\hline \multicolumn{10}{|c|}{ Main Effects $\left(R^{2}=.136, p<.001\right)$} \\
\hline $\mathrm{Ev}$ & $5.06[1.16,8.96]$ & 1.99 & $0.011 *$ & $1.47[-4.09,7.02]$ & 2.83 & 0.604 & $1.50[-4.06,7.05]$ & 2.83 & 0.597 \\
\hline Consis & $20.09[16.19,23.99]$ & 1.99 & $<0.001 *$ & $16.53[11.00,22.06]$ & 2.82 & $<0.001 *$ & $16.59[11.05,22.12]$ & 2.82 & $<0.001 *$ \\
\hline $\mathrm{NC}$ & $-0.11[-0.17,-0.05]$ & 0.03 & $0.001 *$ & $-0.16[-0.27,-0.05]$ & 0.06 & $0.006 *$ & $-0.14[-0.27,-0.01]$ & 0.07 & $0.040 *$ \\
\hline \multicolumn{10}{|c|}{2 -way $\mathrm{X}\left(R^{2}=.142, p<.001\right)$} \\
\hline Ev X Consis & & & & $7.00[-0.79,14.80]$ & 3.97 & 0.078 & $6.97[-0.83,14.77]$ & 3.97 & 0.080 \\
\hline Ev X NC & & & & $0.10[-0.02,0.22]$ & 0.06 & 0.115 & $0.06[-0.12,0.24]$ & 0.09 & 0.492 \\
\hline Consis X NC & & & & $-0.01[-0.14,0.11]$ & 0.06 & 0.824 & $-0.05[-0.23,0.13]$ & 0.09 & 0.570 \\
\hline \multicolumn{10}{|c|}{ 3-way X $\left(R^{2}=.143, p<.001\right)$} \\
\hline Ev X Consis & & & & & & & $0.07[-0.18,0.32]$ & 0.13 & 0.570 \\
\hline
\end{tabular}

Note. $* p<.05$ 
Table 5

Study Two: Effects of Evidence Disclosure (Ev), Consistency of Confession and Case-Facts (Consis) and NC on Participants' Strength of Evidence Ratings

\begin{tabular}{|c|c|c|c|c|c|c|c|c|c|}
\hline \multirow[t]{2}{*}{ IV/Model } & \multicolumn{3}{|c|}{ Block 1} & \multicolumn{3}{|c|}{ Block 2} & \multicolumn{3}{|c|}{ Block 3} \\
\hline & $B[95 \% C I$ of $B]$ & $S E$ & $p$ & $B[95 \% C I$ of $B]$ & $S E$ & $p$ & $B[95 \% C I$ of $B]$ & $S E$ & $p$ \\
\hline \multicolumn{10}{|c|}{ Main Effects $\left(R^{2}=.126, p<.001\right)$} \\
\hline $\mathrm{Ev}$ & $0.21[0.06,0.35]$ & 0.07 & $0.005 *$ & $0.03[-0.17,0.24]$ & 0.10 & 0.742 & $0.04[-0.17,0.24]$ & 0.10 & 0.726 \\
\hline Consis & $0.69[0.54,0.83]$ & 0.07 & $<0.001 *$ & $0.52[0.31,0.72]$ & 0.10 & $<0.001 *$ & $0.52[0.32,0.73]$ & 0.10 & $<0.001 *$ \\
\hline $\mathrm{NC}$ & $-0.004[-0.01,0.00]$ & $<0.01$ & $<0.001 *$ & $-0.01[-0.01,0.00]$ & $<0.01$ & $0.011 *$ & $-0.004[-0.01,0.00]$ & $<0.01$ & 0.121 \\
\hline \multicolumn{10}{|c|}{ 2-way X $\left(R^{2}=.133, p<.001\right)$} \\
\hline Ev X Consis & & & & $0.34[0.05,0.63]$ & 0.15 & $0.021 *$ & $0.34[0.05,0.62]$ & 0.15 & $0.022 *$ \\
\hline Ev X NC & & & & $0.001[0.00,0.01]$ & $<0.01$ & 0.591 & $-0.002[-0.01,0.01]$ & $<0.01$ & 0.650 \\
\hline Consis X NC & & & & $0.001[0.00,0.01]$ & $<0.01$ & 0.773 & $-0.002[-0.01,0.00]$ & $<0.01$ & 0.516 \\
\hline \multicolumn{10}{|c|}{ 3-way X $\left(R^{2}=.134, p<.001\right)$} \\
\hline Ev X Consis & $\mathrm{X} \mathrm{NC}$ & & & & & & $0.01[0.00,0.01]$ & 0.01 & 0.250 \\
\hline
\end{tabular}

Note. $* p<.05$ 
Table 6

Study Two: Effects of Evidence Disclosure (Ev), Consistency of Confession and Case-Facts (Consis) and NC on Participants' Reliability of the Confession Ratings

\begin{tabular}{|c|c|c|c|c|c|c|c|c|c|}
\hline \multirow[t]{2}{*}{ IV/Model } & \multicolumn{3}{|c|}{ Block 1} & \multicolumn{3}{|c|}{ Block 2} & \multicolumn{3}{|c|}{ Block 3} \\
\hline & $B[95 \% C I$ of $B]$ & $S E$ & $p$ & $B[95 \% C I$ of $B]$ & $S E$ & $p$ & $B[95 \% C I$ of $B]$ & $S E$ & $p$ \\
\hline \multicolumn{10}{|c|}{ Main Effects $\left(R^{2}=.129, p<.001\right)$} \\
\hline Ev & $0.25[0.08,0.42]$ & 0.09 & $0.005 *$ & $-0.04[-0.28,0.20]$ & 0.12 & 0.742 & $-0.04[-0.28,0.20]$ & 0.12 & 0.754 \\
\hline Consis & $0.79[0.62,0.96]$ & 0.09 & $<0.001 *$ & $0.51[0.27,0.75]$ & 0.12 & $<0.001 *$ & $0.51[0.27,0.76]$ & 0.12 & $<0.001 *$ \\
\hline $\mathrm{NC}$ & $-0.01[-0.01,0.00]$ & $<0.01$ & $<0.001 *$ & $-0.01[-0.01,0.00]$ & $<0.01$ & $0.040^{*}$ & $-0.004[-0.01,0.00]$ & $<0.01$ & 0.163 \\
\hline \multicolumn{10}{|c|}{2 -way $\mathrm{X}\left(R^{2}=.144, p<.001\right)$} \\
\hline Ev X Consis & & & & $0.56[0.22,0.90]$ & 0.17 & $0.001 *$ & $0.56[0.22,0.90]$ & 0.17 & $0.001 *$ \\
\hline Ev X NC & & & & $0.002[0.00,0.01]$ & $<0.01$ & 0.503 & $0.00[-0.01,0.01]$ & $<0.01$ & 0.981 \\
\hline Consis X NC & & & & $-0.004[-0.01,0.00]$ & $<0.01$ & 0.156 & $-0.01[-0.01,0.00]$ & $<0.01$ & 0.145 \\
\hline \multicolumn{10}{|c|}{ 3-way $\mathrm{X}\left(R^{2}=.144, p<.001\right)$} \\
\hline Ev X Consis & $\mathrm{X} \mathrm{NC}$ & & & & & & $0.004[-0.01,0.01]$ & 0.01 & 0.500 \\
\hline
\end{tabular}

Note. $* p<.05$ 
Table 7

Study Two: Effects of Evidence Disclosure (Ev), Consistency of Confession and Case-Facts (Consis) and NC on Participants' Impression of the Interrogation Ratings

\begin{tabular}{|c|c|c|c|c|c|c|c|c|c|}
\hline \multirow[t]{2}{*}{ IV/Model } & \multicolumn{3}{|c|}{ Block 1} & \multicolumn{3}{|c|}{ Block 2} & \multicolumn{3}{|c|}{ Block 3} \\
\hline & $B[95 \% C I$ of $B]$ & $S E$ & $p$ & $B[95 \% C I$ of $B]$ & $S E$ & $p$ & $B[95 \% C I$ of $B]$ & $S E$ & $p$ \\
\hline \multicolumn{10}{|c|}{ Main Effects $\left(R^{2}=.124, p<.001\right)$} \\
\hline $\mathrm{Ev}$ & $0.49[0.33,0.65]$ & 0.08 & $<0.001 *$ & $0.19[-0.04,0.41]$ & 0.11 & 0.102 & $0.19[-0.04,0.41]$ & 0.11 & 0.101 \\
\hline Consis & $0.57[0.42,0.73]$ & 0.08 & $<0.001 *$ & $0.27[0.05,0.50]$ & 0.11 & $0.016^{*}$ & $0.28[0.05,0.50]$ & 0.11 & $0.016^{*}$ \\
\hline $\mathrm{NC}$ & $-0.01[-0.01,0.00]$ & $<0.01$ & $<0.001 *$ & $-0.004[-0.01,0.00]$ & $<0.01$ & 0.077 & $-0.004[-0.01,0.00]$ & $<0.01$ & 0.169 \\
\hline \multicolumn{10}{|c|}{2 -way $\mathrm{X}\left(R^{2}=.141, p<.001\right)$} \\
\hline Ev X Consis & & & & $0.60[0.28,0.91]$ & 0.16 & $<0.001 *$ & $0.60[0.28,0.91]$ & 0.16 & $<0.001 *$ \\
\hline Ev X NC & & & & $0.00[-0.01,0.01]$ & $<0.01$ & 0.969 & $-0.001[-0.01,0.01]$ & $<0.01$ & 0.842 \\
\hline Consis X NC & & & & $-0.003[-0.01,0.00]$ & $<0.01$ & 0.226 & $-0.004[-0.01,0.00]$ & $<0.01$ & 0.319 \\
\hline \multicolumn{10}{|c|}{ 3-way X $\left(R^{2}=.141, p<.001\right)$} \\
\hline Ev X Consis & $\mathrm{X} \mathrm{NC}$ & & & & & & $0.001[-0.01,0.01]$ & 0.01 & 0.810 \\
\hline
\end{tabular}

Note. $* p<.05$ 
Table 8

Study Two: Effects of Evidence Disclosure (Ev), Consistency of Confession and Case-Facts (Consis) and NC on Participants' Ratings of the Defendant's Character

\begin{tabular}{|c|c|c|c|c|c|c|c|c|c|}
\hline \multirow[t]{2}{*}{ IV/Model } & \multicolumn{3}{|c|}{ Block 1} & \multicolumn{3}{|c|}{ Block 2} & \multicolumn{3}{|c|}{ Block 3} \\
\hline & $B[95 \% C I$ of $B]$ & $S E$ & $p$ & $B[95 \% C I$ of $B]$ & $S E$ & $p$ & $B[95 \% C I$ of $B]$ & $S E$ & $p$ \\
\hline \multicolumn{10}{|c|}{ Main Effects $\left(R^{2}=.085, p<.001\right)$} \\
\hline $\mathrm{Ev}$ & $-0.17[-0.33,-0.01]$ & 0.08 & $0.033 *$ & $-0.04[-0.26,0.18]$ & 0.11 & 0.723 & $-0.04[-0.26,0.19]$ & 0.11 & 0.736 \\
\hline Consis & $-0.57[-0.72,-0.41]$ & 0.08 & $<0.001 *$ & $-0.44[-0.66,-0.22]$ & 0.11 & $<0.001 *$ & $-0.43[-0.66,-0.21]$ & 0.11 & $<0.001 *$ \\
\hline $\mathrm{NC}$ & $0.01[0.00,0.01]$ & $<0.01$ & $<0.001 *$ & $0.004[0.00,0.01]$ & $<0.01$ & 0.052 & $0.01[0.00,0.01]$ & $<0.01$ & 0.052 \\
\hline \multicolumn{10}{|c|}{ 2-way X $\left(R^{2}=.088, p<.001\right)$} \\
\hline Ev X Consis & & & & $-0.26[-0.57,0.06]$ & 0.16 & 0.107 & $-0.26[-0.57,0.05]$ & 0.16 & 0.104 \\
\hline Ev X NC & & & & $0.00[-0.01,0.01]$ & $<0.01$ & 0.881 & $-0.001[-0.01,0.01]$ & $<0.01$ & 0.767 \\
\hline Consis X NC & & & & $0.00[-0.01,0.01]$ & $<0.01$ & 0.933 & $-0.001[-0.01,0.01]$ & $<0.01$ & 0.727 \\
\hline \multicolumn{10}{|c|}{ 3-way X $\left(R^{2}=.089, p<.001\right)$} \\
\hline Ev X Consis & $\mathrm{X} \mathrm{NC}$ & & & & & & $0.003[-0.01,0.01]$ & 0.01 & 0.581 \\
\hline
\end{tabular}

Note. $* p<.05$ 